\title{
Cáncer pulmonar primario: características operativas de diferentes modalidades diagnósticas utilizadas en el Hospital Universitario Fundación Santa Fe de Bogotá entre los años 2012-2016
}

José S. Arias, Luis G. García-Herreros, Álvaro Morales, Mónica P. Caicedo

Santa Fe de Bogotá

Hospital Universitario Fundación Santa Fe de Bogotá, Universidad del Rosario, Universidad de los Andes.

\section{Introducción}

El cáncer de pulmón es la primera causa de mortalidad por cáncer a nivel mundial. A pesar de esto, en Colombia existe una información limitada sobre las características de esta enfermedad, que ocupa el quinto lugar en incidencia y segundo lugar de mortalidad por cáncer. En la actualidad existe una variedad importante de modalidades diagnósticas y su selección dependerá de su disponibilidad, utilidad, seguridad, rendimiento y costo.

\section{Objetivos}

Describir las características clínicas de los pacientes con cáncer de pulmón primario en pacientes atendidos en el hospital universitario Fundación Santa Fe de Bogotá y determinar el rendimiento diagnostico de las diferentes modalidades diagnósticas utilizadas.

Materiales y métodos

Estudio de tipo corte transversal donde se incluyeron todos los pacientes con diagnóstico histopatológico de cáncer pulmonar primario entre los años 2012 y 2016 atendidos en la Fundación Santa Fe de Bogotá.

\section{Resultados}

Se analizó la información correspondiente a 83 pacientes con diagnóstico de cáncer pulmonar primario y de 166 procedimientos a los cuales fueron sometidos.

\begin{tabular}{|c|c|c|}
\hline \multirow{3}{*}{$\begin{array}{l}\text { Edad, media } \pm \text { ds } \\
\text { Mujeres, No (\%) }\end{array}$} & \multirow{2}{*}{\multicolumn{2}{|c|}{$64 \pm 13$}} \\
\hline & & \\
\hline & 43 & $(51,8 \%)$ \\
\hline \multicolumn{3}{|c|}{ Estado nutricional, No $(\%)^{*}$} \\
\hline Bajo peso & 9 & $(12,5 \%)$ \\
\hline Peso normal & 34 & $(47,2 \%$ \\
\hline Sobrepeso & 25 & $(34,7 \%)$ \\
\hline Obesidad & 4 & $(5,6 \%)$ \\
\hline \multicolumn{3}{|c|}{ Tipo de cáncer, No (\%) } \\
\hline No microcítico & 76 & $(91,6 \%)$ \\
\hline Otros & 6 & $(7,2 \%)$ \\
\hline Microcítico & 1 & $(1,2 \%)$ \\
\hline \multicolumn{3}{|c|}{ Subtipo de cáncer, No (\%) } \\
\hline Adenocarcinoma & 71 & $(85,5 \%)$ \\
\hline Otros & 7 & $(8,4 \%)$ \\
\hline Escamocelular & 5 & $(6,0 \%)$ \\
\hline Células grandes & 0 & $(0,0 \%)$ \\
\hline \multicolumn{3}{|c|}{ Clasificación 8 va edición, No $(\%)^{* *}$} \\
\hline IA-B & 22 & $(26,8 \%)$ \\
\hline IIA-B & 4 & $(4,9 \%)$ \\
\hline IIIA-C & 14 & $(17,1 \%)$ \\
\hline IVA-B & 42 & $(51,2 \%)$ \\
\hline
\end{tabular}

La media de edad al momento del diagnóstico fue de 64 años y el 52,8\% tenían algún grado de malnutrición. El tipo histológico más frecuente fue el adenocarcinoma $(85,5 \%)$. El rendimiento de la biopsia transbronquial, transtorácica y de otros órganos fue de $66.7 \%, 90.9 \%$ y $100 \%$ respectivamente (Figura 2 ). El análisis estratificado mostró que la biopsia transbronquial alcanzó un rendimiento de $77.3 \%$ en lesiones centrales y $46.1 \%$ en periféricas; en lesiones mayores a $3 \mathrm{~cm}$ fue $72 \%$ y en menores fue $58.8 \%$. Finalmente, en lesiones periféricas menores a $3 \mathrm{~cm}$ el rendimiento fue de $33.3 \%$.

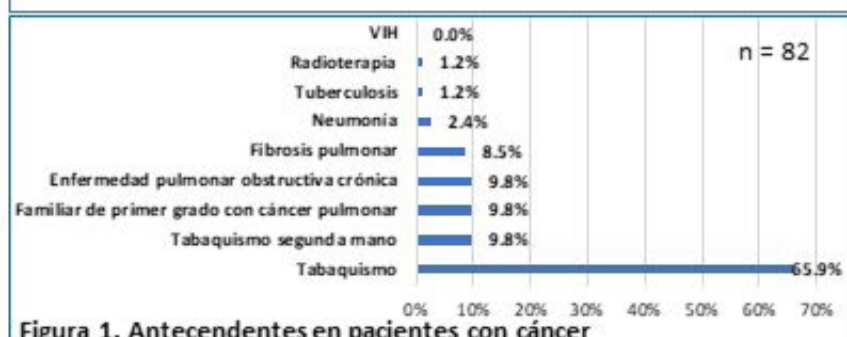

Figura 1. Antecendentes en pacientes con cáncer

pulmonar primario.

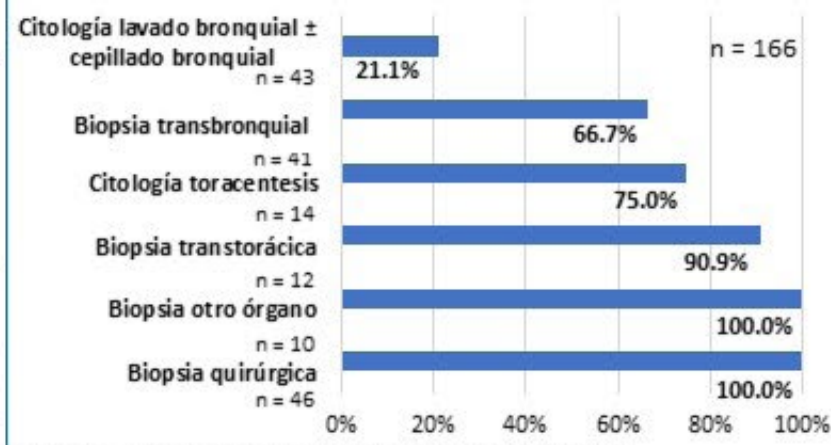

Figura 2. Rendimiento procedimientos diagnósticos realizados en pacientes con cancer pulmonar primario.

\section{Conclusiones}

Los procedimientos que derivaron en estudio histológico diagnóstico tuvieron una sensibilidad similar a la reportada por estudios internacionales. Se debe considerar la aplicación de estrategias diagnósticas complementarias, con el fin de aumentar el rendimiento diagnóstico general y en particular, de las lesiones con mejor pronóstico (menor $\mathrm{N}$ ), tales como las lesiones periféricas menores a $3 \mathrm{~cm}$.

\section{Referencias}

1. Pardo C, Cendales R, Incidencia, mort alid ad y prevalencia de Cáncer en Colombia 2007-2011 [Internet]. Vol. 1, Instituto Nacional De Cancerologia. 2015.148 p.

2. Rivera MP, Mehta AC, Watidi MM. Establishing the diagnosis of lung cancer: Diagnosis and management of lung cancer, 3 rd ed: American coll ege of chest physicians evidence-based clinical practice guidelines, Chest (Internet). 2013:143(5 SUPPL)ye142S-e165S. 